\title{
Transitioning to Client/Server: Using a Temporal Framework to Study Organizational Change
}

\author{
S. Sawyer \\ School of Information Studies \\ Syracuse University \\ Syracuse, New York 13244-4100 USA \\ Tel: (315) 443-4473 \\ Fax: (315) 443-5806 \\ E-mail: ssawyer@cat.syr.edu \\ R. Southwick \\ School of Information Studies \\ Syracuse University \\ Syracuse, New York 13244-4100 USA \\ Tel: (315) 443-4473 \\ Fax: (315) 443-5806 \\ E-mail:rmsouthw@mailbox.syr.edu
}

\begin{abstract}
Research on the management of information systems has rarely conducted in-depth investigations on the problematic role of time in the development and implementation of these systems. When the research has done this, it has interpreted time in an objective, linear sense. This paper calls attention to the existence of not only the objective nature, but also the subjective nature of time in the organizational change surrounding the implementation of new information systems. This paper draws its empirical material from an on-going study of the implementation and use of distributed computing-based systems at a mid-sized university (MSU).
\end{abstract}


Implementing client/server networks illuminates three themes that contribute to the dual objective/subjective nature of time at MSU: (1) client/ server computing is a complex web of technologies and involves people who are struggling to reach a stable, productive state; (2) the development of a client/server project is a discontinuous process; and (3) because of the number of stakeholders involved in the implementation of client/server systems, there are "temporal asymmetries" - that is, differences in how these people themselves perceive and experience time. For managers, to understand the subjective, perceptual nature of time can provide a managerial lever. For researchers, these temporal asymmetries make a difference to how data are collected and interpreted.

Research on the management of information systems has rarely conducted in-depth investigations on the problematic role of time in the development and implementation of these systems. Where the research has done this, it has interpreted that time is interpreted in an objective, linear sense (e.g., Robey and Newman 1996). The purpose of this paper is to illuminate the existence of not only the objective nature but also the subjective nature of time in the organizational change surrounding the implementation of new information systems. We draw our empirical material from an ongoing, multi-year study of the implementation and use of distributed computing-based systems at a mid-sized university (MSU). MSU is in the process of a campus-wide transition from a mainframe-computing architecture to a client/server architecture.

This paper's perspective of time as having a subjective, and not just objective, nature refers to how everyday people in their everyday lives actually experience time (Macey 1989; Friedman 1990). In most of the management and organizational literature, time is measured in divisible units that mark the passing of events - a Newtonian conceptualization. However, recent literature has acknowledged that time is also subjectively perceived (e.g., Vinton 1992). In this non-Newtonian conceptualization, everyday people in everyday life perceive time as shaped by what they are doing, whom they are with, and the numerous other factors that shape the everyday contexts in which they live. Consistent with this additional, perceptual nature of time is also the notion that time can move at different speeds, depending on the social context of the human actors. The issue of variable celerity has implications for both practitioners and researchers. For practitioners, the variations in subjective interpretations of time can be a source of managerial leverage as well as organizational dilemmas. For researchers, the variations affect how they would proceed in collecting and interpreting data.

\section{THE DUAL NATURE OF TIME IN THE IMPLEMENTATION OF CLIENT/SERVER COMPUTING}

The implementation of client/server computing, at least at our field site, illuminates three themes that contribute to the dual nature of time: 
(1) Client/server computing is a complex web of technologies and involves people who are struggling to reach a stable, productive state. This complex web ties together multiple stakeholders, involving high levels of interdependence. These stakeholders are both within, and without, the organization that is implementing the distributed system.

(2) The development of a client/server project is a discontinuous process. The dependencies among stakeholders make possible many starts, stops, and redirections in the implementation effort.

(3) Because of the number of stakeholders involved in the implementation of client/ server systems, there are "temporal asymmetries" - that is, differences in how these people themselves perceive and experience time. These differing perceptions and experiences can, in turn, create the potential for conflict between different groups of stakeholders.

To flesh out the three themes, this paper continues in five sections. The second section defines client/server computing and describes the research site. The third section part builds the case for the dual nature of time by drawing on the research literature relevant to our field work at MSU. The fourth section outlines our research approach. The fifth section presents our field observations, which we use in our attempt to provide rich, empirical illustrations of the three themes. Pulling back from the specifics of our case, the final section provides a general discussion on how to account for the dual perspectives on time.

\section{TRANSITIONING TO CLIENT/SERVER COMPUTING AT MID-SIZED UNIVERSITY}

Underlying the present research is our belief that distributed computing, embodied in technology such as client/server networks, represents a distinct and dramatic change in computing infrastructure. A computing infrastructure encompasses hardware systems, software systems, workers who serve these systems, and norms of use pertaining to these systems. In this way, computing infrastructures act as a web, tying an organization together (Kling and Scacchi 1982; Kling 1995).

\subsection{Client/Server Computing}

Client/server computing is currently the dominant model for new forms of distributed computing infrastructures. The technical architecture of client/server computing is substantially different from that of mainframe computing (Hall 1994). A fundamental premise of client-server computing is that the total capacity of the distributed servers and workstations exceeds that of the mainframes they replace. This is made possible by the ability of the technology to allow two or more computers to share the accessing, processing, and storing of data through cooperative and interactive use of 
software applications. Data-sharing imposes a heavy requirement on the technical capabilities of the network. This includes high-speed, broad-band data communication to connect clients with servers so the latter can run applications cooperatively. This new architecture moves software applications, and the associated processing of data, closer to the user (via the client software) and provides opportunities for computer processing that can be faster, more efficient, and more effective, hence improving the quality of service.

This broadening of computer processing - from centralized mainframes to an interconnected network of distributed computers - necessitates, in turn, significant organizational change. Physically distributing an organization's information processing capability has the consequence of also distributing the organization's information resources. From the organization's perspective, this means that the distribution of information, via technical innovation, will alter social and administrative practices (Zuboff 1988; Orlikowski 1991). In other words, changes in technology mean changes in the social definitions of what that technology is and what it does (Kling and Scacchi 1982).

\subsection{Mid-Sized University}

MSU is a private, research-oriented school. It enjoys high name recognition, nationally and internationally. MSU's administrative and organizational structures can be considered typical for American universities of nearly 18,000 students and nearly 3,700 employees. By 1993, three environmental factors had created a situation demanding MSU's attention. Those who administered MSU's computing infrastructure faced (1) an increasing workload required of MSU's mainframe systems, (2) a restrictive reliance on MSU's outdated legacy systems, and (3) a nearly unmanageable tangle of administrative and academic networks, characterized by overlapping links and disparate technologies.

These issues regarding computing are typical of most academic computing systems (Alpert 1985; El-Khawis 1995; McClure and Lopata 1996). Facing this scenario, MSU's CIO made the decision to revamp the computing infrastructure so as to take advantage of new client/server technology. The CIO reflected that this was "as much a decision on saving money as it was freeing ourselves from commitments we no longer wanted."

For two reasons, we viewed the situation at MSU to be especially favorable for studying organizational change in the context of a client/server implementation. The first is that, at the time of our decision to establish the research stream of which this study is a part, MSU was still in the relatively early stages of its multi-year implementation. Thus, we were presented with the opportunity to follow the project from the planning/design phase of implementation (pre-installation) through the eventual, actual use of the technology (post-installation). The second reason is that the technology implementation at MSU is organization-wide (campus-wide) in scope. The project called for a complete transition from the existing mainframe-dominated 
architecture to a client/server architecture, where the transition was targeted to span several years. In order to reach this objective, the project plan established many smaller department-specific projects (e.g., admissions, financial aid, etc.). The multiproject structure allowed us opportunities for research involving multiple levels of analysis within the organization and with vendors.

\section{TIME}

Given the turbulent and discontinuous environment for developing and deploying client/server computing in general, we believe that time can provide a common thread with which to organize observations and interpretations of client-server implementation. In this section of the paper, we examine how temporal elements help form the basis for our observations and interpretations.

Perhaps the most obvious influence of time in the transition to client/server computing at MSU derives from the fact that MSU's client/server initiative involves a perpetual process of product development. Participating in this development process are departmental system users, technologists within MSU, and external vendors (especially of client/server software). Time forms one structure in which the interaction among these groups unfolds.

Associated with the organizational process of deploying client/server computing, and the systems relying upon it, are artifacts that the organizational actors themselves use to impose administrative order. These are the tools of project management. The most obvious example is milestone charts, which are instruments for measuring time. Milestone charts also reflect a longstanding tradition in organizational studies, where time is understood to be a commodity that is objective, linear, homogenous, and divisible (partitionable by rational human mental process) and that has value commensurate with its divisible parts (Hassard 1996).

\subsection{The Dual Nature of Time}

With respect to our research, we recognize a problem in such conceptions of time. In the first place, the client/server project at MSU appears to be neither linear nor homogenous. As we will describe, project development at MSU has reflected discontinuity and turbulence. Individual client/server projects have often exhibited abrupt changes in direction (nonlinearity) and have not generally maintained a consistent pace (nonhomogeneity). This presents a problem for management instruments in which development (measured in objective time) is assumed to be incremental.

Gersick (1988 1989) has attempted to account for the nonhomogenous nature of time as it affects decision-making and problem-solving. Applying theory developed in natural science (Eldrege and Gould 1972), Gersick advances a model of "punctuated equilibrium" for group-level theory to explain the discontinuous, and apparently 
spontaneous, patterns and pace of activity exhibited in the course of group development projects. The punctuated equilibrium model differs from linear models of group activity in which processes are assumed to be linear and incrementally additive (Gersick 1989).

Gersick's model straddles the dual conceptions of time: objective time and subjective (socially constructed) time. This is also the case for Friedman and for Macey, who make distinctions between time as objectively measured and time as subjectively experienced. Bucciarelli (1988) posits two worlds in the temporal process of engineering design: an "object-world" defined by topicality and a "process-world" defined by social narrative. We may easily extend his analysis to the software development process. The object-world refers to the physical elements of computer technology, such as hardware and software. The process-world refers to the "world of dialogue and negotiation, of social exchange, laughter, gossip, banter - all that which is everpresent in design, but whose significance is generally discounted" (pp. 96-97).

Although research on the management of information systems has rarely conducted in-depth investigations on the problematic role of time in the development and implementation of these systems, the need to account for the socially defined aspect of time in order to bring about a successful systems implementation has been recognized for some time. In reflections on his experiences with software development projects, Brooks (1972) illustrates how traditional conceptions of time (i.e., as linear and additive) may lead to inaccurate hypotheses within the complexity of a social context. As reflected in the title of his book, The Mythical Man-Month, he relates how assuming that one might hasten the completion of a project by assigning more people to it was not only wrong, but also likely to produce the opposite effect. The lesson from Brooks is that, in software development projects, where social complexity interacts with the demands of system development tasks, success also depends on a recognition of social factors - among them, the way time is seen and structured by the participants themselves.

In addition to recognizing time as instrumental to the software development process, we also see it as an element in a conceptual framework for examining the power struggle among users, technologists, and vendors. Here, we refer to Barley's (1988) perspective on time which builds on the work of Zerubavel $(1979,1981)$. He examines the interaction of technology and organizational structure. His longitudinal study of radiology departments involved in new technology implementation serves to highlight that temporal order can structure the conflict between the technicians (as users) and the radiologists (as users). He posits a recurring dynamic between external, objective aspects of temporal order (structural) and its social constructedness (interpretive). Barley also makes a case for technology-based temporal order affecting the way individuals and groups interpret their work. He posits that temporal asymmetry may be a source of conflict between organizational groups.

Our perspective in the present research posits that management seeks stability and order in the deployment of information technology, or IT, resources. For this reason we prefer the term synchronous rather than symmetrous. In the implementation of 
client/server systems, we point to three sets of relations in which temporal perceptions may be asynchronous. The first exists between the vendors (the developers of software) and the technologists (members of the organization's information systems, or IS, group). The second exists between the vendors and the users. The third exists between the technologists and the users.

The first set of relations is new to the technologists at MSU. One of the directives regarding the client/server implementation was to buy software, not build it. The result has been that vendors are far more integral than previously to MSU's computing infrastructure. The technologists have become responsible for overseeing what they used to do for a living and their role turned into one of change agentry. With regard to the second set of relations, the asynchronous user/developer temporal relationship has always existed. However, because the developers (who are now vendors) are not co-located at MSU, it is now a relationship at a distance. The final set of relations, between the users and the technologists, has changed in that these two groups now share many of the same concerns. However, the long history between the two seems to mask some of the similarities they now share. In other words, the historical perception by users - that IS is not very responsive or accessible - is not changed by the fact that IS now includes them in every decision about the vendor packages. Users have trouble believing that IS has "the same vision."

These three sets of relations suggest a dual nature to time. As Jones (1988, p. 21) says, "All human events occur in time. But the character of those events and the time in which they occur vary widely from person to person, from culture to culture." Each set of the three sets of relations acknowledges the objective, measured chronology of time, but each also highlights the subjective and omni-present nature of time. Our observations confirm the presence of this subjective component. Further, we note the potential for temporal asymmetry to persist between developers and users of the client/server technology. This may have the effect of leading to inaccurate decisions in the users' evaluation of systems since perceptions of development time are structured according to traditional development cycles, rather than the rapid pace of client/server development. For instance, one vendor was selected over another because of a strong perception that this vendor was further along in the development cycle than the other vendors. One of the other vendors argued that "it is the nature of client/server in its present state that learning takes place through implementation."

We further extend this argument to suggest that the temporal asymmetries between developers and users creates a degree of control by developers over users (e.g., Markus 1983; Markus and Bjørn-Anderson 1987; Kling and Iacono 1984). Related to this point is that the user may maintain the perception that the length of time they are involved with a vendor is indicative of the degree of development of a product. In other words, they perceive a process which is linear and cumulative when it is, in fact, discontinuous and constantly reinitiated.

Because of the volatility of innovation in client/server technology, many applications persist in beta form. Weick (1990) has previously suggested that new technologies follow a pattern of development different from that of older technologies. The 
high level of mental interpretation and subsequent uncertainty in knowledge of the process serve to result in a situation in which "implementation often is the means by which the technology itself is designed" (p. 8). We see this as standard for client/server development. Beta versions of software are often the norm with upgrades occurring in beta-stage applications. As we will discuss, one of the vendors providing software for MSU releases a new version each month! This sets the stage for temporal discontinuities to persist. This means that the objective nature of time provides for measurement, even as the subjective nature of time sets the stage for conflict. This dual nature of time serves as a lens for interpreting our observations at MSU.

\section{OUR RESEARCH APPROACH}

In this part of the paper, we describe our research approach. Our motivations are concerned with documenting sequences of events and a process of change over time, rather than with attempting to capture organizational events as set of factors which relate to one another through causal interaction (Mohr 1982). We made the following four assumptions in conducting our research.

(1) Our perspective on change is social. While change may manifest itself in some physical form or artifact, we believe that, in order to develop useful knowledge of the phenomenon, it is necessary to elicit the socially constructed interpretations of the organizational actors which they develop through their social interactions (Markus 1983).

(2) An actor's interpretations are part of a larger, dynamic social context and, therefore, must be interpreted as situationally dependent. This perspective incorporates the social and physical aspects of computing into the concept of an infrastructure: the web of computing (Kling and Scacchi 1982; Kling 1995).

(3) The situationally dependent, socially interpreted foundation for social (organizational) action makes prediction based on a single event or a single actor's actions impossible. In other words, we take an emergent perspective on the relationship between information technology and the organization (Markus and Robey 1988).

(4) In taking an interpretive perspective, we believe that we, as researchers, cannot be detached from the social context. Therefore, our observations are necessarily subjective, and this has implications for the conduct of the research (Barley 1990).

Following the objectives and assumptions outlined above, we have employed a longitudinal, field-based methodology for studying organizational change at MSU. Zuboff $(1988$, p. 423) began her own discussion of her methodology by saying "Behind every method is a belief." Our belief is that longitudinal, in situ field work is an appropriate approach, well-suited for research that seeks to understand the evolving process of implementing new technologies. There has been an increased 
interest in longitudinal, field-based, and observer-centered research for the study of information technology in organizations (Kling 1980; Markus and Robey 1988; Pettigrew 1990; Lee and Markus 1995). There are many reasons for this emerging interest. Two of the most salient are (1) the limitations on what we know about technology's effects in organizations and (2) the speed at which technology changes (Van Maanen 1995).

\subsection{Data Collection}

In collecting data, we spanned individual and organizational levels of analysis. At the individual level, we looked at how client/server systems are being interpreted. At the organizational level, our interest was to see how these client/server systems affect the web of computing already in place at MSU. In doing this, we sought to emphasize the potentially differing perspectives that users, technologists, and vendors have. We began our fieldwork with a ten month period of gaining access to, and the confidence of, the site's employees. This early phase provided the context for the data collection and analysis in the current study.

We employed two primary methods for collecting data: interviews and observation. Interviews vary by level of structure, with most being semi-structured and openended. Typically these are taped and transcribed. All interviewees are asked if they mind being taped; if they are reluctant, we do not tape the interview. Our field notes record data collected from unobtrusive observations, from participation in committees and meetings, and from informal social interactions. There are two types of field notes for each observation: the first is a chronology of events and actions; the second is a more free-flowing account of perceptions, stories, and anecdotes. The chronology serves as a record of observations. The account serves as a record of the observer's perceptions. We also had access to formal documents and the archives of the client/server change. This includes e-mail, work records, and archival memos and reports. We used these materials to help establish our understanding of the context and organizational milieu.

\subsection{Present Status}

MSU initiated its mainframe-to-client/server transition project in February 1993. We commenced our research effort in February 1995. To date, our activities have centered on participation with, and observations of, committees formed to work on specific aspects of the client/server initiative; ongoing interviews with managers and workers (both IS and line); and document/records collection. This includes more than sixty hours of meetings and over fifty interviews (averaging about 65 minutes each). We also have more than 600 documents (e-mail, memos, handouts, and reports). Five people have participated in data collection, while two have been part of the project from its inception. 
In the process of coordinating and tracking the data collection effort, we have made use of vignettes and stories to help develop an understanding of what we are observing. Through this informal effort, shared themes have been emerging. These take the shape of narratives and anecdotes, woven together from our data. Thus, these findings reflect an interim understanding, a valuable step in doing qualitative analysis (Miles 1979, 1990).

\section{OBSERVATIONS FROM THE CLIENT/SERVER IMPLEMENTATION AT MSU}

We began this paper by positing three related themes in the implementation of client/server computing that highlight the dual nature of time: (1) client/server computing is a complex web of technologies and involves people who are struggling to reach a stable, productive state; (2) the development of a client/server project is a discontinuous process; and (3) because of the number of stakeholders involved in the implementation of client/server systems, there are "temporal asymmetries" - that is, differences in how these people themselves perceive and experience time. These differing perceptions and experiences can, in turn, create the potential for conflict between different groups of stakeholders.

1. Client/server computing is a complex web of technologies and involves people who are struggling to reach a stable, productive state.

An underlying idea of client/server computing is that individual nodes on the network are able to exchange data, or facilitate the cooperative processing of data, in a direct, peer-to-peer relationship (Hall 1994). This stands in contrast to the idea of mainframe computing, in which computing activity is typically directed through, and controlled by, a centralized "master" processor. The individual nodes of the client/server network are typically computers which may run applications, provide access to databases, control printer activity, etc. In order for there to be direct, peerto-peer connectivity there must be interoperability between the various hardware and software components (i.e., the architectures and platforms). This requirement poses a significant technical challenge.

In large part due to this need for interoperability, there is a fast-paced, continuous process of software development and redesign to fulfill the promise of client/server. New products necessitate modifications of old products, making this a seemingly selfperpetuating process. The breadth of innovation is accentuated by the fact that the concept of a computing network, especially in a technical sense, now commonly transcends organizational boundaries. The interest in Internet technology and the national information infrastructure (NII) has widened the scope of interoperability. This, in turn, has also contributed to accelerating the pace of product innovation.

In light of the frenzied pace of innovation in distributed computing, it becomes an even more daunting challenge for any organization to stay abreast of such technical 
change, and, consequently, to maintain technical integrity (interoperability) between the various segments of the broader organizational infrastructure. This accelerating pace sets the stage for temporal asymmetries to exist between vendors, users, and technologists. Technological developments have forced MSU's IS staff to shift its focus from mainframe systems to client/server systems, and the technological staff struggles to comprehend this new arena. The vendors, who have embraced the client/server architecture, are positioned to respond to these technological developments more easily than the IS staff at MSU. The users are the least able to keep pace, and this creates the potential for time-based conflicts.

Our observations to date suggest that, at this stage in the technological evolution of client/server computing, the transition from mainframe computing to client/server computing will continue to be challenging for all groups and individuals involved with the implementation project at MSU. This has been especially evident in the meetings of oversight committees where progress on individual subprojects appears to be continually undermined by the necessity to devote time to solve technical problems. For example, the director of the client/server implementation says of the weekly IT directors' meeting 'I'm not comfortable, yet, with the directors. People talk about the technology, they talk about the budgets, they talk about the dynamics of [our] group. We never talk about the transition [the set of projects that are implementing the client/server systems]." The information center manager says "We don't plan, we don't pay much attention to anything but the new technology. [We] never talk about how to use it."

While this situation may not be unique or surprising, given the nascent state of client/sever technology, we believe that there are unique characteristics of this form of computing which compound the problem. In particular, the distributed nature of client/server applies to the social structure of the organization, not just to the spatial configuration of the physical technology. In other words, client/server computing enables a greater degree of freedom for technical independence within organizational subunits. Individual departments within MSU are adopting different strategies for computing, e.g., using WindowsNT instead of Novell as the network operating system. This makes it more difficult for the technologists, who are attempting to coordinate the computing infrastructure, to maintain a sense of control over it. As the director of the physical network states, "In some sense, [this is] the most strategic decision we made [i.e., allowing a department to break from the standard network configuration]."

2. The development of the client/server project is a discontinuous process.

Despite the techniques and instruments used by the IS department in its attempt to invoke or impose a temporally defined order for internal development efforts (such as PERT and Gantt charts), the actual client/server project at MSU is far from controllable. There are two reasons for this. The first is that development schedules now are 
controlled by the vendors, albeit with input from the technologists and users at MSU. The second reason is that applications often are not available on the market when MSU needs them.

Here, temporal asymmetries are created by expectations. MSU's users and technologists understand that the client/server market is evolving rapidly. However, the products that they need are not available. This creates a paradox in time: the quick pace of change is not providing what they need. For the vendors, the ability to respond to changing technology is moderated by their ability to produce products. This may be less about the technology than their own management skills, but the effect is that the users and technologists at MSU cannot keep up technologically. And the vendors cannot deliver products that are based on the technology they seem to know so well.

For example, MSU predicated its original project plan on having key student processing functions available in an integrated client/server system by Fall 1996. However, there were no viable products when they looked at the market in 1994. Since then, the two dominant players have moved at different speeds. The group MSU had chosen fell behind schedule and has recently bought out its contract. The other is about to bring a product to market, which MSU has decided to adopt. A second example is the continued need of a reasonably-priced security package that will provide single entry passwords to multiple applications. In the absence of this product, several other projects have been delayed.

These two examples also illustrate how the development and deployment of client/server infrastructure can proceed in fits and starts, with numerous changes in direction, rather than following a linear path of gradual and steady progress. MSU's project plans, and most deadlines, are flexible (and often not met). They are steadily revised to account for which products are ready and what sequence of dependencies between projects can be met. While this makes sense at a strategic level, for the users this translates into a steady discounting of any plans produced by the technologists (whether external vendors or internal IS). For internal IS, this puts them in a unique place: they know how hard it is to plan development yet they must act as overseers to vendors and as advocates for users. At the same time, they often serve as apologists for the vendors. The CIO, after visiting the senior management of one (severely delayed) vendor implementation said, "I'm sick of being their whipping boy."

As suggested above, many factors - internal and external to the organization - may contribute either to stimulate, retard, or even derail the development of client/server products. For example, software upgrades in this environment are frequent. One project has a new update to its software about every three weeks. From the vendor's perspective, they are developing software at breakneck speed and being responsive. The users interpret this as sloppy development. Furthermore, client/server systems often exhibit less stability than their mainframe ancestors. For the user, this creates a churning feeling. The lead implementor for a system with changes every three weeks calls it "computing on roller skates." 
3. Because of the number of stakeholders involved in the implementation of client/ server systems, there are "temporal asymmetries" - that is, differences in how these people themselves perceive and experience time.

One way to view these differing perceptions of time is to focus on the differences between groups. A temporal structure provides order to the daily conduct of work. Temporal structures show up in the rituals of coffee breaks, in how long meetings last, and in what it means to be early or late. These temporal structures are often implicit and so are not explicitly discussed when meeting with members of other groups (Barley 1988). For example, in speaking with various managers and administrators within MSU, we hear repeated reference to Fall 1997 as the target date for a complete transition from the mainframe system to a client/server computing system. This is the date originally set by the CIO to coincide with the termination of agreements with mainframe contractors. The temporal asymmetry that we perceive here exists between those who are most actively involved in the transition and those who are not. The former see this as a "drop-dead" date. The latter see this date as unreachable and, thus, flexible. Since this is never explicitly discussed, conflicts over the importance of different projects arise.

We have examined three groups' perspectives on development. The first two groups, vendors and MSU's IS staff, represent two subsets of the technologist's perspective. The vendors are building the client/server applications to be used at MSU, while the MSU IS staff are the computer and the network administration personnel (and their managers) who facilitate the integration of client/server applications into the existing computing infrastructure. The third group consists of the users who work with MSU's IS staff and MSU's vendors, so as to enable the integration of the client/server applications into the existing work life of the organizational units that will be using the systems.

Much of our data collection to date has focused on the technologists in the IS department, who have been attempting to form a bridge between the technology (personified through vendors) and their clients in the organization. These technologists are having to learn the client/server technologies even as the technologies are changing. The IS director of the implementation effort has said "we are one person deep at most skills. Sometimes we don't even have that." This means that very little is stable for the technologists. The greatest urgency is felt among the IS managers, the people ultimately responsible for a successful implementation. In their effort to implement successfully a large, complex, and often turbulent project, they struggle to convey this sense of urgency to others within and outside the organization. Vendors are also concerned with delivery of their product. But this delivery is set in the context of the vendor's overall needs, not MSU's. The users and their managers are interested in improvements that they have been led to expect. However, they have no interest in increased work or in "working hard so we can wait to change" says one senior administrator. 
Users, who had grown accustomed to the stable, if limited, services in the mainframe environment, also do not know what to expect. Said one administrator, while learning about the data warehouse, "I'm not sure what this [system] can do. Nor am I sure what it can't. I just don't know." The support that technologists provided to users is not as certain in the new environment. And users do not know what to expect. This increased uncertainty for users as well as technologists is a new factor in their relationship at MSU.

\section{IMPLICATIONS FOR RESEARCH: ACCOUNTING FOR TIME}

Perhaps the most significant of temporal asymmetries is that the pace of time changes for each of these groups based on the issues confronting them. Vendors are rushing products, users are chafing at delays, and technologists are trying to mediate. And all three groups have differing temporal structures that define what rushing, chafing, and trying mean. Because perceptions of time are built from the social worlds in which these people live, these perceptions are implicit. Given the power of objective time measures, these subjective perceptions stay hidden. Still, objective time is a complication to the variations in subjective time. It is subjective time's temporal asymmetries that give rise to contentions among the three stakeholder groups. For managers, understanding the subjective, perceptual, nature of time can provide a lever. For researchers, these temporal asymmetries affect how data is collected and interpreted. These points are discussed in the following sections.

\subsection{Time as a Lever for Managers}

The temporal asymmetries which exist among vendors, users, and technologists can serve as a lever for managers in two ways. One point of leverage is to use the differing perceptions of time as a mechanism to instill urgency in the different groups by highlighting differences. These "artificial" crises are one form of short-term motivation. A second point of leverage is to use these temporal asymmetries as insulation. For example, vendors move slower than the technologists would like, regarding changes that the vendors make in the software. This is so the vendor can maintain control over its code. MSU technologists do the same with the users, explaining to these users how the extra time spent will result in better solutions.

\subsection{Time and Data Collection}

These observations on time's dual nature have implications for research in two ways. First, these findings suggest that the rapidly changing nature of client/server development deserves more attention. Second, these findings suggest that researchers must 
explicitly account for both objective and subjective time in data collection. These are discussed below.

The rapidly changing nature of client/server development deserves more attention. All implementations are unique, and the increased interdependence and number of stakeholders that client/server systems demands heighten this uniqueness. This means that the implications of the dual nature of time can be best understood in the field and not in an environment controlled by the researcher (McGrath 1988). This encourages observations and interviews across objective time as the basis of research on information systems implementation. However, while the employment of longitudinal research methods may be assumed to provide such an accounting, it may do so only in a limited way unless it is theoretically specified by the researchers prior to data collection (Monge 1990). Longitudinal methods may follow dynamic processes across time, rather than take snapshots, but do not necessarily incorporate a theoretic basis for time. Moreover, most social scientists see time in the Newtonian sense: metaphorically represented as an "arrow," imposing a linear order or sequence on events.

Many social scientists have rather uncritically incorporated this orderly time of Newton into their own models, treating time as a background or hidden dimension. It becomes an attribute of the natural universe that is simply there (or "ticking away") as a parameter, marker, or line against which events and activities unfold in an orderly fashion and are then measured by the analyst. [Dubinskas 1988, p. 7]

Such an interpretation fails to account for time as a socially constructed phenomenon. In other words, time in this objective sense does not recognize that different individuals or groups may interpret the temporal structure of a given situation differently. Or, from our perspective, organizational members' reports concerning time may vary according to situational factors. It becomes important to understand the subjective nuance of this time in context.

Explicitly accounting for subjective and objective time in data collection. We had set out to capture a chronology of events: an objective accounting for time. What we have learned is that the interpretive nature of time provides another perspective on the way in which events transpire. This is what Bucciarelli calls the process world. We believe that a primary power of longitudinal research is the opportunity to focus on the subjective aspects of time. These nuances on time's subjective nature arise from reflecting on the data, from understanding the broader context, and from comparing narratives and observations across perspectives and levels of analysis. This can be better enabled by modifying data collection efforts in two ways. The first way is to more explicitly account for the time lines of the various constituents. The second way is to record perceptions of temporal asymmetries as part of the field notes following each observation.

More explicitly accounting for the time lines of the various constituents. To do this, we believe that a time line should be developed for each group. Doing this can highlight key assumptions and make explicit the way the different groups experience 
time. This provides a mechanism to compare the various perspectives both as they change as time passes and as they coexist with other constituencies' perspectives.

Recording perceptions of temporal asymmetries as part of the field notes following each observation. Our present method of completing field notes is to produce two sets. The first is a chronology (as we see it) of how the observation or interview proceeded. The second is a summary of our perceptions pertaining to that observation and our current thinking. In this second, more expository, set, we can more carefully record the ways in which time is presented or discussed in these observations/interviews. The goal is to describe better the temporal context; this effort should assist us in interpreting the process-world of time. In this state, the focus of the research needs to remain interpretive. Thus, while we continue to draw on existing work, this rapidity of change provides a chance to elaborate and extend our understanding of how change occurs in organizations (Vaughn 1992).

\subsection{Client/Server: Technology or Metaphor?}

Our position at the beginning of this study was that it is necessary to incorporate the rules, norms, values, and even the subjective perceptions of the people involved, not just the physical attributes of the system, in order to reach an understanding of the information technology. We made the distinction between technology, which has more to do with the hardware and software, and computing infrastructure, which we understand to include the social or cultural aspects as well. Our study to date has reaffirmed this definition of IT, extending the concept of infrastructure to embody time as one manifestation of socio-cultural life.

The new distributed computing technologies, represented by client/server in our work, present significant obstacles to understanding the effects of computing infrastructures on organizations. This is true for the designers and users of these systems and for organizational researchers. One recurrent question is "How will we know whether the impacts on the organization are caused by the client/server aspect of the technology?" The present findings suggest the irrelevance of such questions which imply a causal relationship between technology and organizational change (i.e., the technological imperative). The world of client/server is a world of metaphor (e.g., data warehouses and icons). Client/server is not a uniquely distinguishable technology; witness the difficulty one encounters in trying to obtain a consensus regarding its definition. For instance, when asked, one manager responded that client/server is "just one more icon on my screen."

In establishing how client/server computing is involved in organizational change, we began a chronology, tying events to a calendar to help organize and interpret them. This has helped us to understand how time is both a social construction and an objective measure (Berger and Luckmann 1967; Macey 1989). That is, time is both objectively measured - by the clock and calendar - and subjectively experienced - by both participants and researchers. For us, the differences in how people see time have 
arisen from attempts to see the world through their eyes, and this is the essence of interpretive work.

\section{REFERENCES}

Alpert, D. (1985). "Performance and Paralysis: The Organizational Context of the American Research University." Journal of Higher Education, Volume 56, Number 3, pp. 242-281.

Barley, S. R. (1988). "On Technology, Time and Social Order: Technically Induced Change in the Temporal Organization of Radiological Work." In Frank A. Dubinskas (Editor), Making Time: Ethnographies of High-Technology Organizations. Philadelphia: Temple University Press, pp. 123-169.

Barley, S. R. (1990). "Images of Imaging: Notes on Doing Longitudinal Fieldwork." Organization Science, Volume 1, Number 3, pp. 220-249.

Berger, P. L., and Luckmann, T. (1967). The Social Construction of Reality: A Treatise in the Sociology of Knowledge. Garden City, New York: Doubleday.

Brooks, F. (1972). The Mythical Man-Month: Essays on Software Engineering. Reading, Massachusetts: Addison-Wesley.

Bucciarelli, L. L. (1988). "Engineering Design Process." In Frank A. Dubinskas (Editor), Making Time: Ethnographies of High-Technology Organizations. Philadelphia: Temple University Press, pp. 92-122.

Dubinskas, F. A. (1988). "Cultural Constructions: The Many Faces of Time." In Frank A. Dubinskas (Editor), Making Time: Ethnographies of High-Technology Organizations. Philadelphia: Temple University Press, pp. 3-38.

El-Khawis, E. (1995). Campus Trends: 1995. Higher Education Panel Report, Number 85. Washington DC: American Council on Education.

Eldrege, N., and Gould, S. J. (1972). "Punctuated Equilibria: An Alternative to Phyletic Gradualism." In T. J. Schopf (Editor), Models in Paleobiology. San Francisco: Freeman, Cooper and Co., pp. 82-115.

Friedman, M. (1990). About Time. Cambridge, Massachusetts: MIT Press.

Gersick, C. J. G. (1988). "Time and Transition in Work Teams: Toward a New Model of Group Development." Academy of Management Journal, Volume 31, pp. 9-41.

Gersick, C. J. G. (1989). "Marking Time: Predictable Transitions in Task Groups." Academy of Management Journal, Volume 32, Number 2, pp. 274-309.

Hall, C. L. (1994). Technical Foundations of Client/Server Systems. New York: John Wiley and Sons.

Hassard, J. (1996). "Images of Time in Work and Organization." In S. R. Clegg, C. Hardy and W. R. Nord (Editors), Handbook of Organization Studies. London: Sage Publications, pp. 581-598. 
Jones, J. (1988). "Cultural Differences in Temporal Perspectives: Instrumental and Expressive Behaviors in Time." In. J. McGrath (Editor), The Social Psychology of Time: New Perspectives. Newbury Park, California: Sage, pp. 21-38.

Kling, R. (1980). "Social Analyses of Computing: Theoretical Perspectives in Recent Empirical Research.” Computing Surveys, Volume 12, pp. 61-110.

Kling, R. (1995). "Behind the Terminal: The Critical Role of Computing Infrastructure in Effective Information Systems' Development and Use." In W. Cotterman and J. Senn (Editors), Challenges and Strategies for Research in Systems Development. London: John Wiley and Sons.

Kling, R., and. Iacono, S. (1984). "Computing as an Occasion for Social Control." Journal of Social Issues, Volume 40, Number 3, pp. 77-96.

Kling, R., and Scacchi, W. (1982). "The Web of Computing: Computing Technology as Social Organization." Advances in Computers, Volume 21.

Lee, A., and, Markus, M. L. (1995). "Call for Papers: Intensive Research and Information Systems: Using Qualitative, Interpretive, and Case Methods to Study the Role of Information Technology in the Management and Use of Knowledge." MIS Quarterly, Volume 19, Number 1, pp. 125-126.

Macey, S. (1989). The Dynamics of Progress: Time, Method, and Measure. Athens, Georgia: The University of Georgia Press.

Markus, M. L. (1983). "Power, Politics, and MIS Implementation." Communications of the ACM, Volume 26, Number 5, pp. 430-444.

Markus, M. L., and Bjørn-Anderson, N. (1987). "Power Over Users: Its Exercise by System Professionals." Communications of the ACM, Volume 30, Number 6, pp. 498-504.

Markus, M. L., and Robey, D. (1988). "Information Technology and Organizational Change: Causal Structure in Theory and Research." Management Science, Volume 34, Number 5, pp.

McGrath, J. (1988). "The Place of Time in Social Psychology." In. J. McGrath (Editor), The Social Psychology of Time: New Perspectives. Newbury Park, California: Sage, pp. 21-38.

McClure, C., and Lopata, C. (1996). Assessing the Academic Networked Environment: Strategies and Options. Washington, DC: Association of Research Libraries.

Miles, M. (1979). "Qualitative Data as an Attractive Nuisance: The Problem of Analysis." Administrative Science Quarterly, Volume 24, pp. 590-610.

Miles, M. (1990). "New Methods for Qualitative Data Collection and Analysis: Vignettes and Pre-structured Cases." Qualitative Studies in Education, Volume 3, Number 1, pp. 37-51.

Mohr, L. B. (1982). Explaining Organizational Behavior. San Francisco: JosseyBass.

Monge, P. R. (1990). "Theoretical and Analytical Issues in Studying Organizational Processes." Organization Science, Volume 1, Number 4, pp. 406-430. 
Orlikowski, W. J. (1991). "Integrated Information Environment or Matrix of Control? The Contradictory Implications of Information Technology." Accounting Management and Information Technology, Volume 1, Number 1, pp. 9-42.

Pettigrew, A. (1990). "Longitudinal Field Research on Change." Organization Science, Volume 1, Number 3, pp. 267-292.

Robey, D., and Newman, R. (1996). "Sequential Patterns in Information Systems Development: An Application of a Social Process Model." ACM Transactions on Information Systems, Volume 14, Number 1, pp.

Van Manaan, J. (1995). "Style as Theory." Organization Science, Volume 6, pp. 132-143.

Vaughan, D. (1992). "Theory Elaboration: The Heuristics of Case Analysis." In C. C. Ragin and H. S. Becker (Editors), What is a Case: Exploring the Foundations of Social Inquiry. Cambridge, England: Cambridge University Press.

Vinton, D. (1992). "A New Look at Time, Speed, and the Manager." Academy of Management Executive, Volume 6, Number 4, pp. 7-16.

Weick, K. E. (1990). "Technology as Equivoque: Sensemaking and New Technologies." In P. S. Goodman, L. S. Sproull and Associates (Editors), Technology and Organizations. San Fransisco: Jossey-Bass, pp. 1-44.

Zerubavel, E. (1979). Patterns of Time in Hospital Life. Chicago: University of Chicago Press.

Zerubavel, E. (1981). Hidden Rhythms: Schedules and Calendars in Social Life. Chicago: University of Chicago Press.

Zuboff, S. (1988). In the Age of the Smart Machine: The Future of Work And Power. New York: Basic Books.

\section{BIOGRAPHY}

Steve Sawyer is an Assistant Professor at Syracuse University's School of Information Studies. His research focuses on how people work together and how they use information technology. Present research includes investigating how software development can be improved through attending to the social aspects of working together and studying how people adapt to working with distributed computing applications (e.g., work-life in the era of client/server computing). Dr. Sawyer is a member of the INFORMS, IEEE, ACM, and USRowing.

Richard Southwick is a Ph.D. student at the Syracuse University School of Information Studies. Current research focuses on IT-based organizational change using longitudinal methods of inquiry. His dissertation research is in progress involving a study of academic libraries transitioning from mainframe to client/server technology. $\mathrm{He}$ is also interested in the information-seeking behaviors of users of information retrieval systems. 